\title{
ИССЛЕДОВАНИЕ МЕТОДОВ СИНТЕЗА, СТРОЕНИЯ И СВОЙСТВ КОМПЛЕКСОВ ФЛАВОНОИДОВ С ИОНАМИ МЕТАЛЛОВ. СООБЩЕНИЕ 4. ИЗУЧЕНИЕ РЕАКЦИИ КОМПЛЕКСООБРАЗОВАНИЯ ИОНОВ $\mathrm{Ca}^{2+}$ С ДИГИДРОКВЕРЦЕТИНОМ
}

\author{
() Е.В. Столповская", Н.Н. Трофимова, В.А. Бабкин
}

Иркутский институт химии им. А.Е. Фаворского СО РАН, ул. Фаворского, 1, Иркутск, 664033 (Россия), e-mail: stel@irioch.irk.ru

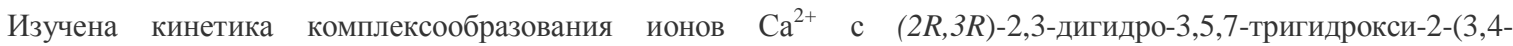
дигидроксифенил)-4H-1-бензопиран-4-оном (дигидрокверцетином) в водной среде. Исследовано влияние условий проведения реакции - мольного соотношения исходных реагентов и их начальных концентраций, аниона кальциевой соли, pH раствора, растворителя, продолжительности реакции на состав и выход комплексного соединения. Установлено, что реакция комплексообразования происходит при $\mathrm{pH} \geq 8$, и стехиометрическое соотношение металл : флавоноидный лиганд $(1: 1)$ в составе комплекса определяется в первую минуту реакции. Оптимизация условий реакции образования кальциевого комплекса дигидрокверцетина позволяет получить продукт со стабильным составом и выходом до $70 \%$.

Ключевые слова: комплексообразование, комплексные соединения, дигидрокверцетин, ионы кальция, кинетика реакции, оптимизация, выход продукта.

\section{Введение}

Актуальность изучения металлокомплексов флавоноидов обусловлена широким спектром биологических и прикладных свойств этих соединений. Сочетание биологической активности свободных флавоноидов со свойствами ионов металлов зачастую приводит к проявлению новых видов специфической активности.

Среди многообразия комплексных соединений (КС) ионов различных металлов с природными полифенолами комплексы щелочноземельных металлов изучены недостаточно. Синтезированы магниевые комплексы с дигидрокверцетином (ДКВ) [1], морином [2], магниевые и бериллиевые комплексы с байкалеином [3], кверцетином [3, 4] и его алкилпроизводными [4], бариевое производное на основе ДКВ [5]. Описаны кальциевые комплексы с морином [2], кверцетином и его алкилпроизводными [4]. Полученный в метаноле кальциевый комплекс с морином со стехиометрическим соотношением металл : лиганд $(1: 1)$ представлен как более сильный антиоксидант по сравнению со свободным морином. Введение иона металла увеличивает и антибактериальную активность флавоноида: кальциевый комплекс морина проявляет активность в отношении штаммов S. aureus u S. flavus, в то время как свободный морин активен, причем в меньшей степени, только против $S$. aureus [2]. Образование комплексов из полигидроксифлавонов и полиметоксифлавонов с металлами II группы приводит к получению флуоресцирующих соединений [4], что

Столповская Елена Владимировна - младший научный сотрудник лаборатории химии древесины, e-mail: stel@ irioch.irk.ru

Трофимова Наталья Николаевна - старший научный сотрудник лаборатории химии древесины, кандидат химических наук, e-mail: natrof@ irioch.irk.ru Бабкин Василий Анатольевич - заведующий лабораторией химии древесины, доктор химических наук, професcop, e-mail: babkin@ irioch.irk.ru предполагает возможность создания фотохромофоров на основе природных полифенолов.

Таким образом, получение металлокомплексных соединений на основе флавоноидов является перспективным как для получения новых фармакологически активных соединений, так и для создания новых практически значимых материалов.

\footnotetext{
* Автор, с которым следует вести переписку.
} 
Цель настоящей работы - изучение кинетики комплексообразования ионов $\mathrm{Ca}^{2+}$ с ДКВ и оптимизация условий данной реакции.

\section{Экспериментальная часть}

УФ-спектры регистрировали на спектрофотометре СФ-26 в кюветах $l=1,0$ см. pН-метрию проводили на приборе «Эксперт-рН». Рентгеновский спектральный энергодисперсионный микроскопический анализ (РСЭДМА) выполнен с помощью электронного микроскопа фирмы Hitachi марки ТМ 3000, датчик: X-ray детектор SDD XFlash 430-H.

Содержание ДКВ в анализируемом растворе определяли спектрофотометрически с помощью градуировочного графика [6]. Содержание ионов $\mathrm{Ca}^{2+}$ в исследуемом растворе определяли методом комплексонометрического титрования трилоном Б с мурексидом [7].

Условия синтеза кальциевого комплекса $\mathrm{C}_{15} \mathrm{H}_{14} \mathrm{O}_{9} \mathrm{Ca}$ и установление его структуры приведены в [8].

В качестве исходных реагентов использовали дигидрокверцетин производства ИНПФ ООО «Химия древесины», выделенный из древесины Larix sibirica Ledeb. и L. gmelinii (Rupr.) Rupr. по технологии [9], и кальциевые соли: $\mathrm{Ca}\left(\mathrm{CH}_{3} \mathrm{COO}\right)_{2} \cdot \mathrm{H}_{2} \mathrm{O}, \mathrm{Ca}\left(\mathrm{NO}_{3}\right)_{2} \cdot 4 \mathrm{H}_{2} \mathrm{O}, \mathrm{CaCl}_{2}$ (х.ч.).

Комплексное соединение синтезировали в течение 1 ч при постоянном перемешивании в водной среде при $80{ }^{\circ} \mathrm{C}$, водно-спиртовой и спиртовой средах при $25^{\circ} \mathrm{C}$. $\mathrm{pH}$ растворов доводили до 8,0 добавлением 6,5\% раствора $\mathrm{NH}_{4} \mathrm{OH}$. После охлаждения полученный осадок отфильтровывали, промывали водой или водно-спиртовой смесью или этанолом в зависимости от среды проведения синтеза. Завершали промывание осадка чистым этанолом. Полученный продукт представлял собой порошок зеленовато-коричневого цвета, нерастворимый в воде, этаноле, ацетоне, малорастворимый в ДМСО.

Эквимольные количества $\mathrm{CaCl}_{2}$ и ДКВ $(0,1 \mathrm{M})$ смешивали в водно-этанольном растворе (70\% этанола). Выход 3,5\%. Найдено, \%: С 39,4; Н 3,7; Са 9,7. Вычислено для $\mathrm{C}_{15} \mathrm{H}_{14} \mathrm{O}_{9}$ Са здесь и далее во всех остальных опытах, \%: С 47,6; Н 3,7; О 38,1; Сa 10,6.

Эквимольные количества $\mathrm{Ca}\left(\mathrm{CH}_{3} \mathrm{COO}\right)_{2} \cdot \mathrm{H}_{2} \mathrm{O}$ и ДКВ $(0,1 \mathrm{M})$ смешивали в водно-этанольном растворе (70\% этанола). Выход 13,2\%. Найдено, \%: С 45,6; Н 3,6; Са 9,8.

Эквимольные количества $\mathrm{Ca}\left(\mathrm{NO}_{3}\right)_{2} \cdot 4 \mathrm{H}_{2} \mathrm{O}$ и ДКВ $(0,1 \mathrm{M})$ смешивали в водно-этанольном растворе (70\% этанола). Выход 13,3\%. Найдено, \%: С 45,2; Н 3,9; Са 9,3.

Эквимольные количества $\mathrm{Ca}\left(\mathrm{NO}_{3}\right)_{2} \cdot 4 \mathrm{H}_{2} \mathrm{O}$ и ДКВ $(0,1 \mathrm{M})$ смешивали в этанольном растворе. Выход 49,4\%. Найдено, \%: С 42,5; Н 4,2; Са 10,7.

Эквимольные количества $\mathrm{Ca}\left(\mathrm{NO}_{3}\right)_{2} \cdot 4 \mathrm{H}_{2} \mathrm{O}$ и ДКВ $(0,1 \mathrm{M})$ смешивали в водном растворе. Выход 57,7\%. Найдено, \%: С 45,3; Н 3,9; Са 10,8.

Эквимольные количества $\mathrm{Ca}\left(\mathrm{CH}_{3} \mathrm{COO}\right)_{2} \cdot \mathrm{H}_{2} \mathrm{O}$ и ДКВ $(0,025 \mathrm{M})$ смешивали в водном растворе. Выход 6,6\%. Найдено, \%: С 44,0; Н 3,7; Са 10,6.

Эквимольные количества $\mathrm{Ca}\left(\mathrm{CH}_{3} \mathrm{COO}\right)_{2} \cdot \mathrm{H}_{2} \mathrm{O}$ и ДКВ $(0,05 \mathrm{M})$ смешивали в водном растворе. Выход 22,4\%. Найдено, \%: С 39,3; Н 4,0; Са 10,7.

Эквимольные количества $\mathrm{Ca}\left(\mathrm{CH}_{3} \mathrm{COO}\right)_{2} \cdot \mathrm{H}_{2} \mathrm{O}$ и ДКВ $(0,10 \mathrm{M})$ смешивали в водном растворе. Выход 54,1\%. Найдено, \%: С 45,3; Н 5,1; Са 10,4.

Эквимольные количества $\mathrm{Ca}\left(\mathrm{CH}_{3} \mathrm{COO}\right)_{2} \cdot \mathrm{H}_{2} \mathrm{O}$ и ДКВ $(0,20 \mathrm{M})$ смешивали в водном растворе. Выход 58,9\%. Найдено, \%: С 43,4; Н 3,6; Са 9,3.

ДКВ $(0,10 \mathrm{M})$ смешивали с $\mathrm{Ca}\left(\mathrm{CH}_{3} \mathrm{COO}\right)_{2} \cdot \mathrm{H}_{2} \mathrm{O}$ в водном растворе, исходное мольное соотношение $\mathrm{Ca}^{2+}:$ ДКВ составляло 2 : 1. Выход 58,4\%. Найдено, \%: С 45,1; Н 4,1; Са 11,0.

ДКВ $(0,10 \mathrm{M})$ смешивали с $\mathrm{Ca}\left(\mathrm{CH}_{3} \mathrm{COO}\right)_{2} \cdot \mathrm{H}_{2} \mathrm{O}$ в водном растворе, исходное мольное соотношение $\mathrm{Ca}^{2+}:$ ДКВ составляло 3 : 1. Выход 70,2\%. Найдено, \%: С 44,9; Н 4,1; Сa 10,6.

\section{Обсуждение результатов}

В продолжение исследования методов синтеза, строения и свойств комплексов двухвалентных биогенных металлов с дигидрокверцетином $[6,10,11]$ изучено влияние различных параметров реакции на состав и выход кальциевого комплекса флавоноида. Ранее для кальциевого производного дигидрокверцетина с найденным содержанием кальция $12 \%$ была показана противогриппозная [12] активность, а для комплексного соединения с содержанием металла 11,5\% показаны антиоксидантные [13] свойства. Таким об- 
разом, оптимизация реакции для получения продукта с постоянным содержанием иона металла и высоким выходом имеет практический интерес в целях разработки технологии производства фармакологически активной субстанции на основе КС.

Для изучения кинетики комплексообразования иона кальция с дигидрокверцетином в водной среде, установления стехиометрического состава полученного соединения и определения его стабильности во времени был проведен мониторинг изменения содержания реагирующих веществ в реакционном растворе в течение 150 мин. Исходные реагенты, ацетат кальция моногидрат и ДКВ, были взяты в мольном отношении $1: 1$. На основании полученных данных по разнице концентраций каждого реагента в исходном растворе и в определяемый момент времени были рассчитаны содержания компонентов в составе КС (рис. 1).

Характер кривых демонстрирует, что с первой минуты реакции стехиометрическое соотношение $\mathrm{Ca}^{2+}:$ ДКВ перимента, свидетельствуя об устойчивости полученного комплекса в условиях реакции.

По данным кинетического исследования были рассчитаны масса и выход образующегося соединения в каждый момент времени реакции для ее оптимизации по продолжительности (рис. 2).

Основная масса продукта (81\%) образовывалась в течение первых 60 мин реакции и прирост массы продукта в следующие 90 мин был незначительным, что позволило определить целесообразность проведения реакции в течение 1 ч.

Использование солей $\mathrm{Ca}\left(\mathrm{CH}_{3} \mathrm{COO}\right)_{2} \cdot \mathrm{H}_{2} \mathrm{O}, \mathrm{Ca}\left(\mathrm{NO}_{3}\right)_{2} \cdot 4 \mathrm{H}_{2} \mathrm{O}, \mathrm{CaCl}_{2}$ (х.ч.) для проведения синтезов в качестве источника комплексообразующего иона продиктовано прежде всего их хорошей растворимостью в используемых средах, а также отсутствием влияния этих солей на окислительно-восстановительные, рацемические и иные преобразования флавоноидной молекулы. Выбор водной среды для проведения реакции обусловлен экологической безопасностью технологических процессов, а апробация водно-спиртовых и спиртовых растворов была проведена с целью снижения их энергозатрат. Результаты оценки влияния аниона кальциевой соли и используемого растворителя на состав и выход комплекса в условиях реакции с исходным мольным соотношением $\mathrm{Ca}^{2+}:$ ДКВ $(1: 1)$ приведены в таблице 1.

Показано, что при использовании различных кальциевых солей и растворителей содержание металла в составе комплекса изменяется незначительно и соответствует соединению со стехиометрическим соотношением иона металла и депротонированного флавоноида $(1: 1)$. Проведение реакции в водной среде увеличивает выход продукта более чем в 4 раза по сравнению с использованием водно-спиртовой среды и на $8 \%$ повышает выход комплекса при использовании спиртовой среды.

Важными параметрами реакции являются начальные концентрации реагентов и их исходное мольное соотношение. Были проведены синтезы с использованием концентраций флавоноида и ионов металла и исходных мольных соотношений $\mathrm{Ca}^{2+}:$ ДКВ в диапазонах, представленных в таблице 2. Реакцию проводили в водной среде с использованием ацетата кальция моногидрата в течение 1 ч.

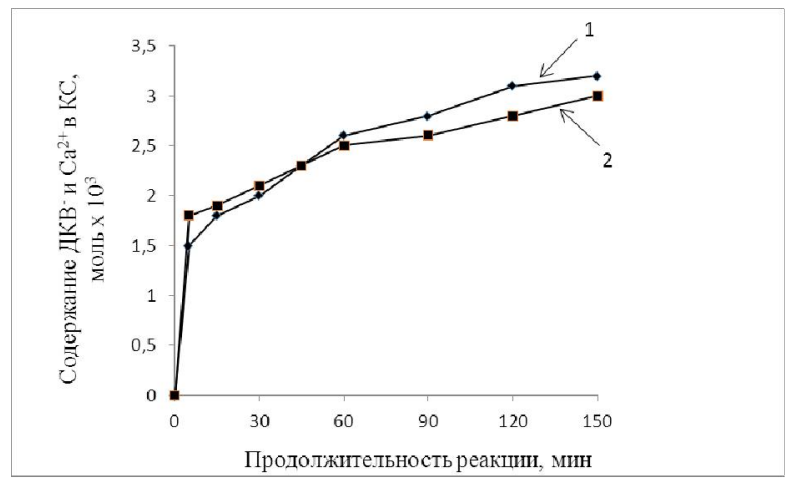

Рис. 1. Изменение содержания ДКВ ${ }^{-} \mathrm{Ca}^{2+}$ в составе комплекса во времени $\left(1-\right.$ ДКВ, моль $\times 10^{3}$, $2-\mathrm{Ca}^{2+}$, моль $\left.\times 10^{3}\right)$

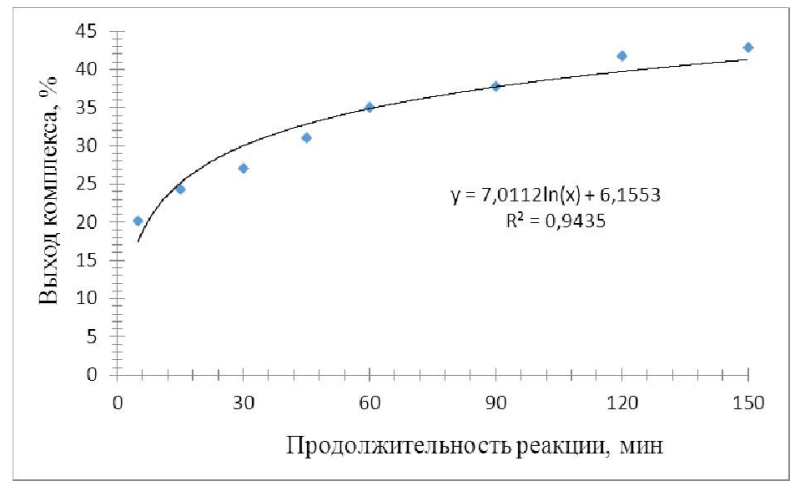

Рис. 2. Зависимость выхода кальциевого КС от продолжительности реакции 
Таблица 1. Влияние аниона кальциевой соли и используемого растворителя на состав и выход комплекса

\begin{tabular}{|c|c|c|c|c|c|c|}
\hline \multirow[b]{2}{*}{$\begin{array}{c}\text { Обра- } \\
\text { зец }\end{array}$} & \multirow[b]{2}{*}{ Кальциевая соль } & \multirow[b]{2}{*}{ Растворитель } & \multirow[b]{2}{*}{$\begin{array}{l}\text { Темпера- } \\
\text { тура, }{ }^{\circ} \mathrm{C}\end{array}$} & \multicolumn{2}{|c|}{ Содержание $\mathrm{Ca}^{2+}$ в комплексе, $\%$} & \multirow{2}{*}{$\begin{array}{c}\text { Выход } \\
\text { продукта, } \\
\%\end{array}$} \\
\hline & & & & $\begin{array}{c}\text { Данные элемент- } \\
\text { ного анализа }\end{array}$ & $\begin{array}{c}\text { Данные } \\
\text { РСЭДМА }\end{array}$ & \\
\hline 1 & $\mathrm{CaCl}_{2}$ & Этанол/вода (7 : 3) & 25 & 9,7 & $\ldots$ & 3,5 \\
\hline 2 & $\mathrm{Ca}\left(\mathrm{CH}_{3} \mathrm{COO}\right)_{2} \cdot \mathrm{H}_{2} \mathrm{O}$ & Этанол/вода (7 : 3) & 25 & 9,8 & 10,6 & 13,2 \\
\hline 3 & $\mathrm{Ca}\left(\mathrm{NO}_{3}\right)_{2} \cdot 4 \mathrm{H}_{2} \mathrm{O}$ & Этанол/вода (7 : 3) & 25 & 9,3 & 9,7 & 13,3 \\
\hline 4 & $\mathrm{Ca}\left(\mathrm{NO}_{3}\right)_{2} \cdot 4 \mathrm{H}_{2} \mathrm{O}$ & Этанол & 25 & 10,7 & 11,0 & 49,4 \\
\hline 5 & $\mathrm{Ca}\left(\mathrm{NO}_{3}\right)_{2} \cdot 4 \mathrm{H}_{2} \mathrm{O}$ & Вода & 80 & 10,8 & 14,2 & 57,7 \\
\hline
\end{tabular}

При использовании эквимольных соотношений исходных реагентов восьмикратное увеличение их концентраций в представленном интервале приводит к увеличению выхода КС в 9 раз. Трехкратный избыток ионов $\mathrm{Ca}^{2+}$ повышает выход продукта на 24\%. Варьирование вышеуказанных параметров реакции не влияет на содержание иона металла в составе комплекса.

Следует отметить, что во всех представленных выше экспериментах кальциевый комплекс образовывался при $\mathrm{pH} \geq 8$. Спектральные изменения дигдрокверцетина водных и водно-спиртовых растворов при различных значениях рН приведены на рисунке 3.

При повышении $\mathrm{pH}$ раствора происходит батохромный сдвиг максимума поглощения ДКВ как в водной, так и в водно-спиртовой средах. Подобные изменения в спектрах поглощения флавонов и флавонолов объясняются их диссоциацией и образованием соответствующих анионов фенолятов [14]. При этом в водной среде диссоциация флавоноида наблюдается с более низких значений рН $(7,7)$, чем в водноспиртовой среде, в которой сдвиг максимума поглощения ДКВ от 290 нм до 330 нм начинается только с рН 9,7. Возможно, этим объясняется более высокий выход комплекса при проведении реакции в водной среде, в которой количество диссоциированных флавоноидов при $\mathrm{pH}$ 8-8,5 значительно больше по сравнению с водно-спиртовой средой и процесс комплексообразования протекает полнее

Таблица 2. Влияние концентраций реагентов и исходных мольных соотношений $\mathrm{Ca}^{2+}$ : ДКВ на содержание иона металла в составе продукта и выход комплекса

\begin{tabular}{|c|c|c|c|c|c|}
\hline \multirow[t]{2}{*}{ Образец } & \multirow[t]{2}{*}{ С(ДКВ), моль/л } & \multirow{2}{*}{$\begin{array}{c}\text { Исходное соот- } \\
\text { ношение } \\
\mathrm{Ca}^{2+}: \text { ДКВ, моль }\end{array}$} & \multicolumn{2}{|c|}{ Содержание $\mathrm{Ca}^{2+}$ в комплексе, $\%$} & \multirow{2}{*}{$\begin{array}{c}\text { Выход продукта, } \\
\%\end{array}$} \\
\hline & & & $\begin{array}{c}\text { Данные элемент- } \\
\text { ного анализа }\end{array}$ & $\begin{array}{c}\text { Данные РСЭД- } \\
\text { МА }\end{array}$ & \\
\hline 6 & 0,025 & $1: 1$ & 10,6 & . & 6,6 \\
\hline 7 & 0,050 & $1: 1$ & 10,7 & 12,5 & 22,4 \\
\hline 8 & 0,100 & $1: 1$ & 10,4 & 11,9 & 54,1 \\
\hline 9 & 0,200 & $1: 1$ & 9,3 & 13,7 & 58,9 \\
\hline 10 & 0,100 & $2: 1$ & 11,0 & 11,7 & 58,4 \\
\hline 11 & 0,100 & $3: 1$ & 10,6 & 11,8 & 70,2 \\
\hline
\end{tabular}

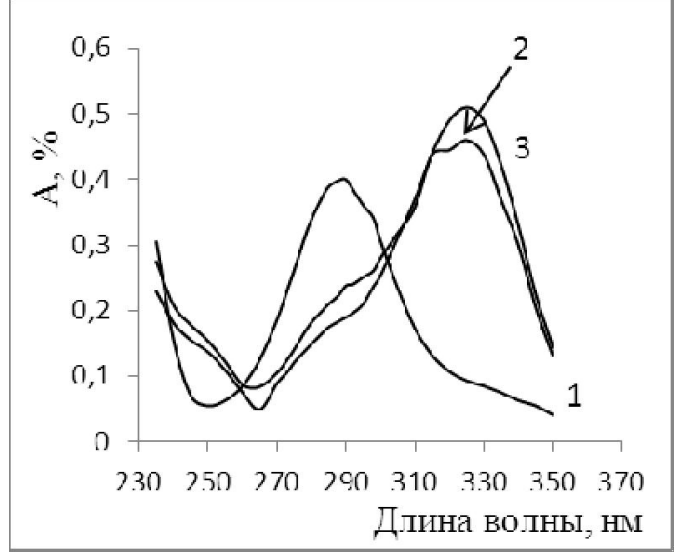

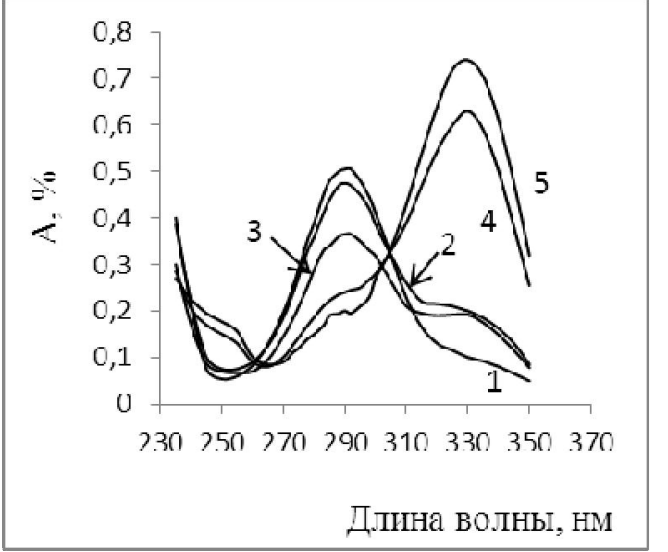

б

Рис. 3. УФ-спектры растворов ДКВ, регистрированные при различных значениях $\mathrm{pH}(1-5,5 ; 2-7,7$; $3-8,5 ; 4-9,7 ; 5-10,9)$ в водной (a) и водно-спиртовой (70\% этанол) (б) средах 


\section{Bbыводы}

На основании кинетических исследований реакции комплексообразования кальция с дигидрокверцетином в водной среде установлено, что стехиометрическое соотношение металл : депротонированный флавоноид в составе комплекса (1:1) устанавливается в первую минуту синтеза и сохраняется в течение эксперимента (150 мин), что говорит о стабильности образующегося соединения в условиях реакции.

Содержание кальция в составе комплекса не зависит от мольного соотношения исходных реагентов и их исходных концентраций, аниона используемой соли, растворителя, используемого для проведения синтеза. Оптимальными условиями реакции образования кальциевого комплекса с дигидрокверцетином с постоянным составом являются водная среда при $80^{\circ} \mathrm{C}, \mathrm{pH} \geq 8$, трехкратный избыток ионов кальция и продолжительность реакции 60 мин.

Основные результаты исследования получены с использованием материально-технической базы Байкальского аналитического иентра коллективного пользования СО РАН.

\section{Список литературы}

1. Мельникова Н.Б., Иоффе И.Д. Взаимодействие дигидрокверцетина с ионами металлов в водных растворах их солей и в изотонических медицинских средах // Химия растительного сырья. 2001. №4. С. 25-33.

2. Panhwar Q.K., Memon Sh. Synthesis and evaluation of antioxidant and antibacterial properties of morin complexes // Journal of Coordination Chemistry. 2011. Vol. 64(12). Pp. 2117-2129.

3. Рошаль А.Д., Сахно Т.В. Теоретический анализ структуры комплексов 5-гидроксифлавонолов с ионами металлов и производными бора // Вестник Харьковского национального университета. 2001. Вып. 7(30). №532. C. $123-129$.

4. Roshal A.D., Sakhno T.V., Verezubova A.A., Ptiagina L.M., Musatov V.I., Wroblewska A., Blazejowski J. Structure, stability and spectral properties of complexes of flavones with metal ions of group II // Functional Materials. 2003. Vol. 10. N3. Pp. 419-426.

5. Kurth E.F., Hergert H.L., Ross J.D. Behavior of Certain 3-Hydroxyflavanones toward Bases and Basic Salts of the Alkali Metals and Ammonia // Journal of the American Chemical Society. 1955. N77. Pp. 1621-1622.

6. Трофимова Н.Н., Столповская Е.В., Бабкин В.А. Исследование методов синтеза, строения и свойств комплексов флавоноидов с ионами металлов. Сообщение 2. Оптимизация реакции комплексообразования цинка с дигидрокверцетином в водной среде // Химия растительного сырья. 2013. №3. С. 73-79.

7. ПНД Ф 14.1; 2.95-97. Количественный химический анализ вод. Методика выполнения измерений массовой концентрации кальция в пробах природных и очищенных сточных вод титриметрическим методом. М., 2004. $17 \mathrm{c}$.

8. Трофимова Н.Н., Столповская Е.В., Бабкин В.А., Федоров С.В., Калабин Г.А., Горяинов С.В., Золотарев Е.Е., Сафронов А.Ю., Кашевский А.В., Житов Р.Г. Строение и электрохимические свойства комплексных соединений металлов с дигидрокверцетином // Химия растительного сырья. 2014. №3. С. 121-131.

9. Патент №2158598 (РФ). Способ получения дигидрокверцетина / В.А. Бабкин, Л.А. Остроухова, Д.В. Бабкин, Ю.А. Малков / 2000.

10. Трофимова Н.Н., Бабкин В.А., Вакульская Т.И., Чупарина Е.В. Исследование методов синтеза, строения и свойств комплексов флавоноидов с ионами металлов. Сообщение 1. Синтез и установление строения комплексов и солей дигидрокверцетина с цинком, медью (II) и кальцием в водных растворах // Химия растительного сырья. 2012. №2. С. 51-62.

11. Трофимова Н.Н., Столповская Е.В., Бабкин В.А. Исследование методов синтеза, строения и свойств комплексов флавоноидов с ионами металлов. Сообщение 3. Изучение кинетики реакции комплексообразования меди с дигидрокверцетином // Химия растительного сырья. 2013. №4. С. 37-43.

12. Патент №2380100 (РФ). Средство для профилактики и лечения гриппа А и В / О.И. Киселёв, В.А. Бабкин, В.В. Зарубаев, Л.А. Остроухова / 2010.

13. Патент №2013121728 (РФ). Способ получения моно- и билигандных комплексных соединений ионов двухвалентных металлов - цинка, меди (II) и кальция с дигидрокверцетином, обладающих усиленной антиоксидантной активностью / Н.Н. Трофимова, В.А. Бабкин, Е.В. Столповская / 2013.

14. Костюк В.А., Потапович А.И. Биорадикалы и биоантиоксиданты. Минск, 2004. 174 с. 
Stolpovskaya E.V., Trofimova N.N., Babkin V.A. THE STUDY OF SYNTHESIS, STRUCTURE AND PROPERTIES OF FLAVONOID COMPLEXES WITH METAL IONS. 4. THE STUDY OF THE CALCIUM COMPLEXATION WITH DIHYDROQUERCETIN

A.E. Favorsky Institute of Chemistry, SB RAS, ul. Favorskogo, 1, Irkutsk, 664033 (Russia), e-mail: stel@irioch.irk.ru

The kinetics of complexation calcium with dihydroquercetin in aqueous solution have been studied for optimization of this reaction. The influence of the molar ratio of the reagents and their initial concentrations, anion of calcium salt, $\mathrm{pH}$, solvent, duration of the reaction for the composition and the yield of the complex compound were investigated. It was found the stoichiometric ratio of metal to ligand flavonoid (1:1) in the complex is determined in the first minute of the reaction at $\mathrm{pH} 8$. Optimization of the complex formation allows to obtain a product with a stable compound and the yield until $70 \%$. the product.

Keywords: complex formation, complex compounds, dihydroquercetin, kinetics of the reaction, optimization, yield of

\section{References}

1. Mel'nikova N.B., Ioffe I.D. Himija rastitel'nogo syr'ja, 2001, no. 4, pp. 25-33. (in Russ.).

2. Panhwar Q.K., Memon Sh. Journal of Coordination Chemistry, 2011, vol. 64(12), pp. 2117-2129.

3. Roshal' A.D., Sahno T.V. Vestnik Har'kovskogo nacional'nogo universiteta, 2001, is. 7(30), no. 532, pp. 123-129. (in Russ.).

4. Roshal A.D., Sakhno T.V., Verezubova A.A., Ptiagina L.M., Musatov V.I., Wroblewska A., Blazejowski J. Functional Materials, 2003, vol. 10, no. 3, pp. 419-426.

5. Kurth E.F., Hergert H.L., Ross J.D. Journal of the American Chemical Society, 1955, no. 77, pp. 1621-1622.

6. Trofimova N.N., Stolpovskaja E.V., Babkin V.A. Himija rastitel'nogo syr'ja, 2013, no. 3, pp. 73-79. (in Russ.).

7. PND F 14.1; 2.95-97. Kolichestvennyj himicheskij analiz vod. Metodika vypolnenija izmerenij massovoj koncentracii kal'cija v probah prirodnyh i ochishhennyh stochnyh vod titrimetricheskim metodom. [PND F 14.1; 2.95-97. Quantitative chemical analysis of water. Methods of measurement of the mass concentration of calcium in samples of natural and treated wastewater titrimetric method.]. Moscow, 2004, 17 p. (in Russ.).

8. Trofimova N.N., Stolpovskaja E.V., Babkin V.A., Fedorov S.V., Kalabin G.A., Gorjainov S.V., Zolotarev E.E., Safronov A.Ju., Kashevskij A.V., Zhitov R.G. Himija rastitel'nogo syr'ja, 2014, no. 3, pp. 121-131. (in Russ.).

9. Patent 2158598 (RU). 2000. (in Russ.).

10. Trofimova N.N., Babkin V.A., Vakul'skaja T.I., Chuparina E.V. Himija rastitel'nogo syr'ja, 2012, no. 2, pp. 51-62. (in Russ.).

11. Trofimova N.N., Stolpovskaja E.V., Babkin V.A. Himija rastitel'nogo syr'ja, 2013, no. 4, pp. 37-43. (in Russ.).

12. Patent 2380100 (RU). 2010. (in Russ.).

13. Patent 2013121728 (RU). 2013. (in Russ.).

14. Kostjuk V.A., Potapovich A.I. Bioradikaly i bioantioksidanty. [Bioradicals and bioantioxidants]. Minsk, 2004, 174 p. (in Russ.).

\footnotetext{
* Corresponding author.
} 